\title{
APLIKASI MEDIA SOSIAL DALAM PEMBELAJARAN BAHASA INGGERIS: PERSEPSI PELAJAR UNIVERSITI
}

\author{
Kee-Man Chuah \\ Centre for Language Studies, Universiti Malaysia Sarawak \\ kmchuah@cls.unimas.my
}

\begin{abstract}
Abstrak
Kewujudan pelbagai aplikasi berasaskan media sosial telah menawarkan satu wadah yang baik untuk para pengajar memaksimumkan penggunaan aplikasi tersebut dalam pendidikan. Kajian ini mengenal pasti persepsi pelajar tentang penggunaan aplikasi media sosial dalam pengajaran Bahasa Inggeris yang melibatkan sejumlah 100 orang pelajar prasiswazah yang mengikuti kursus pengukuhan Bahasa Inggeris. Mereka dikehendaki untuk melibatkan diri dalam aktiviti-aktiviti berasaskan media sosial yang dijalankan dalam laman e-pembelajaran kursus tersebut selama 10 minggu. Pada penghujung minggu ke-10, borang soal selidik diberikan kepada pelajar untuk mengenal pasti persepsi mereka tentang aktiviti-aktiviti yang telah dijalankan. Dapatan kajian menunjukkan para pelajar berpendapat Wiki telah membantu penulisan mereka, manakala video YouTube banyak digunakan untuk meningkatkan penguasaan kemahiran bertutur. Selain itu, kumpulan perbincangan Facebook dianggap berguna untuk pembelajaran tatabahasa dan perkataan. Twitter pula hanya digunakan untuk menerima informasi tentang definisi perkataan. Perbincangan tentang kekuatan dan kelemahan media sosial dalam pembelajaran Bahasa Inggeris dan cadangan untuk meningkatkan potensi aplikasi tersebut juga disertakan.
\end{abstract}

Kata kunci: persepsi, pembelajaran Bahasa Inggeris, media sosial, aplikasi

\section{Learning of English Language via Social Media: University students' perceptions}

\begin{abstract}
The introduction of various social media applications has offered a favourable platform for educators to maximise the use of such tools for language learning. This paper examines student's persceptions on the use of social media applications in English language teaching. In this study, 100 undergraduates enrolled for an English remedial course were required to engage in the online activities provided in the elearning portal for 10 weeks. The portal used various social media tools to assist students' learning. A survey was then carried out at the end of the tenth week. The findings indicated that the students generally benefited from the use of Wiki in enhancing their writing while YouTube videos were extensively used to improve their
\end{abstract}


speaking skills. Facebook group was deemed useful to learn grammar and vocabulary. However, Twitter served mainly as a tool to retrieve updates on the definition of words. Based on the findings, this paper also explores the affordances and constraints of social media in English language learning and proposes several ways how such tools could be leveraged to maximise their potentials.

Keywords: perception, English language learning, social media, applications

\section{Pendahuluan}

Perkembangan pesat teknologi maklumat dan komunikasi telah membolehkan maklumat diterima dengan cepat dengan hanya menggunakan peranti komputer yang mempunyai akses internet. Sebarang maklumat yang diperlukan boleh diperoleh pada bila-bila masa. Kemajuan ini juga telah menyumbang kepada perubahan cara pengajaran dan pembelajaran yang tidak lagi terhad kepada kandungan buku teks mahupun perkara yang disampaikan oleh seseorang guru di dalam kelas. Kop (2011) menjelaskan bahawa satu sumbangan terbesar teknologi internet dalam dunia pendidikan adalah dari segi penyebaran kandungan pembelajaran tanpa sempadan. Pelajar-pelajar boleh melayari laman-laman sesawang yang berguna untuk memantapkan lagi kefahaman mereka tentang sesuatu subjek atau topik.

Dari perspektif pengajaran bahasa berasaskan komputer, pelbagai kajian lepas telah menunjukkan keberkesanan teknologi dalam memantapkan lagi proses pengajaran dan pembelajaran (Weller, 2011). Manakala dalam pengajaran bahasa, Chambers (2010) mengatakan bahawa aplikasi komputer, khususnya internet telah memudahkan lagi pelajar untuk mempelajari tatabahasa dan perbendaharaan kata. Kern (2006) pula berpendapat teknologi berfungsi sebagai perantara antara guru dengan pelajar. Keberkesanan sesuatu teknologi itu dalam proses pengajaran dan pembelajaran banyak bergantung kepada peranan guru. Guru harus bijak menggunakan teknologi yang ada dengan menggunakan pedagogi yang bersesuaian. Hal ini demikian kerana, tanpa perancangan yang rapi, penggunaan teknologi semata-mata tidak akan membantu mencapai objektif pengajaran. Kern (2006) juga berpendapat aplikasi-aplikasi internet perlu dimaksimumkan penggunannya dalam pengajaran bahasa.

Sejajar dengan perkembangan internet, media sosial kini menjadi aplikasi internet yang kian popular. Media sosial ditakrifkan sebagai sekumpulan aplikasi internet yang dibina berasaskan ideologi dan teknologi Web 2.0 yang membenarkan penghasilan dan perkongsian bahan-bahan yang dijana oleh pengguna (Kaplan \& Haenlein, 2010). Populariti media sosial banyak bergantung kepada penglibatan golongan remaja. Wardrip-Fruin dan Montfort (2003) menyatakan bahawa golongan remaja yang terdedah kepada teknologi maklumat pada usia muda lebih terdorong untuk melibatkan diri dalam perkongsian maya, khususnya melalui media sosial. Media sosial juga dianggap mampu membantu pelajar berinteraksi dengan lebih mudah terutamanya dari segi pembelajaran bahasa (Annand, 2011) dan mendapatkan informasi bermanfaat dalam pelbagai format seperti gambar, video 
dan animasi (Azer, 2012). Walau bagaimanapun, Boyd (2010) berpandangan pesimistik terhadap keberkesanan media sosial dalam penyaluran maklumat secara berkesan. Boyd (2010) berpendapat bahawa, walaupun media sosial dapat mengumpulkan beribu-ribu maklumat dalam masa yang singkat, tahap perhatian yang diberikan oleh pengguna adalah sangat rendah, dan kebanyakan maklumat yang dipaparkan melalui media sosial tidak dibaca langsung oleh pengguna.

Kajian tentang penggunaan media sosial sebagai aplikasi dalam pengajaran bahasa masih pada peringkat awal. Kebanyakan kajian lepas lebih tertumpu kepada aplikasi yang membantu pelajar dalam penulisan seperti Wiki dan blog (Huang \& Hung, 2009; Kessler, Bikowski, \& Boggs, 2012). Isu yang selalu timbul dalam kajian lepas ialah kerahsiaan pengguna (Hunter, 2011). Hal ini membataskan kajian yang dapat dijalankan, memandangkan media sosial memerlukan seseorang pengguna untuk memberi maklumat peribadi. Justeru, kajian ini akan menggabungkan aplikasi media sosial dalam laman e-pembelajaran supaya maklumat peribadi peserta kajian tidak akan terdedah kepada umum. Kajian ini juga akan membolehkan pelajar menggunakan aplikasi media sosial dalam pembelajaran Bahasa Inggeris.

\section{Tujuan Kajian}

Kajian ini dijalankan adalah untuk memenuhi objektif-objektif berikut:

i. Mengenal pasti persepsi pelajar tentang penggunaan media sosial dalam pembelajaran Bahasa Inggeris, dan

ii. Mengenal pasti kekuatan dan kelemahan penggunaan media sosial dalam pembelajaran Bahasa Inggeris.

\section{Kaedah Kajian}

Kajian ini melibatkan 100 pelajar prasiswazah yang mengikuti kursus pengukuhan Bahasa Inggeris. Pelajar-pelajar yang terlibat dalam kajian ini dikehendaki terlibat secara aktif dalam aktiviti-aktiviti berasaskan media sosial yang dijalankan melalui laman e-pembelajaran kursus berkenaan. Media sosial yang dipilih ialah Wiki, Facebook, Twitter dan YouTube. Para pelajar perlu melibatkan diri dalam aktivitiaktiviti yang diberikan untuk tempoh 10 minggu. Pada penghujung minggu ke-10, borang soal selidik diberikan kepada pelajar. Mereka dikehendaki menjawab soalansoalan yang diberikan, untuk mengenal pasti pandangan mereka terhadap empat jenis media sosial yang dipilih untuk kajian ini. Maklum balas yang diperoleh akan dikira dan dianalisis mengikut peratusan tertentu iaitu bersetuju dan tidak bersetuju berdasarkan pernyataan soalan yang diberi.

\section{Dapatan dan Perbincangan}

Dapatan kajian ini akan dibahagikan kepada dua bahagian. Bahagian pertama ialah persepsi pelajar tentang media sosial dalam pengajaran Bahasa Inggeris, manakala 
bahagian kedua ialah senarai kekuatan dan kelemahan media sosial dalam proses pengajaran Bahasa Inggeris.

\section{Persepsi pelajar tentang penggunaan media sosial}

Jadual 1

Persepsi pelajar terhadap Wiki

\begin{tabular}{lcc}
\hline \multicolumn{1}{c}{ Pernyataan } & Setuju & Tidak Setuju \\
\hline $\begin{array}{l}\text { Saya bekerjasama dengan rakan-rakan dalam } \\
\text { melengkap Wiki. }\end{array}$ & $58 \%$ & $42 \%$ \\
$\begin{array}{l}\text { Saya menyertai aktiviti Wiki untuk } \\
\text { meningkatkan kemahiran menulis. }\end{array}$ & $65 \%$ & $35 \%$ \\
$\begin{array}{l}\text { Saya memberi lebih sumbangan dalam aktiviti } \\
\text { Wiki berbanding di dalam kelas }\end{array}$ & $53 \%$ & $47 \%$ \\
\hline
\end{tabular}

Jadual 1 menunjukkan persepsi pelajar tentang penggunaan Wiki sebagai aplikasi yang membantu mereka menulis karangan Bahasa Inggeris. Secara amnya, pelajar memberikan maklum balas yang positif terhadap penggunaan Wiki. Sebanyak 58\% daripada mereka bersetuju bahawa mereka bekerjasama dengan rakan-rakan yang lain dalam melengkapkan maklumat yang diperlukan dalam Wiki dan $65 \%$ pelajar juga beranggapan Wiki telah meningkatkan kemahiran menulis mereka, manakala $53 \%$ menyatakan bahawa mereka memberi lebih sumbangan dalam aktiviti Wiki berbanding aktiviti yang dijalankan di dalam kelas. Dapatan ini menyokong hasil kajian Kessler (2009) yang menunjukkan bahawa penggunaan Wiki telah membantu pelajar bekerjasama untuk mempelajari struktur penulisan yang betul. Aplikasi ini membolehkan pelajar memantapkan lagi penulisan mereka dengan bantuan rakan-rakan tanpa keperluan pengawasan daripada pelajar.

Jadual 2

Persepsi pelajar terhadap Facebook

\begin{tabular}{|c|c|c|}
\hline Pernyataan & Setuju & Tidak Setuju \\
\hline Saya berbincang dengan aktif melalui & & \\
\hline Facebook & $85 \%$ & $15 \%$ \\
\hline $\begin{array}{l}\text { Saya suka berbincang dengan rakan melalui } \\
\text { Facebook }\end{array}$ & $83 \%$ & $17 \%$ \\
\hline $\begin{array}{l}\text { Saya mengambil peluang untuk menulis lebih } \\
\text { banyak dalam Facebook }\end{array}$ & $67 \%$ & $33 \%$ \\
\hline
\end{tabular}

Jadual 2 menunjukkan persepsi pelajar terhadap penggunaan Facebook dalam sistem e-pembelajaran. Facebook digunakan sebagai wadah untuk perbincangan ilmiah dan sosial. Dapatan yang diperoleh jelas menunjukkan populariti Facebook dalam kalangan pelajar. Sebanyak $85 \%$ pelajar mengakui bahawa mereka aktif berbincang melalui media tersebut dan $83 \%$ menyatakan 
mereka suka berbincang dengan rakan melalui Facebook. Walau bagaimanapun, hanya $67 \%$ berpendapat mereka mengambil peluang untuk menulis lebih banyak dalam Facebook berbanding media lain. Melalui pemerhatian yang dijalankan, pelajar-pelajar didapati lebih cenderung untuk berkongsi pandangan melalui Facebook. Pelajar yang selalunya pasif di dalam kelas juga dilihat lebih aktif apabila berbincang melalui aplikasi media sosial tersebut. Senario ini dilihat sejajar dengan hasil kajian Roblyer, McDaniel, Webb, Herman, dan Witty (2010), iaitu pelajar dikatakan lebih menyukai perbincangan melalui Facebook kerana aplikasi ini merapatkan jurang antara ahli kumpulan dan memudahkan perkongsian pendapat.

Jadual 3

Persepsi pelajar terhadap Twitter

\begin{tabular}{lcc}
\hline \multicolumn{1}{c}{ Pernyataan } & Setuju & Tidak Setuju \\
\hline $\begin{array}{l}\text { Saya mengikuti Twitter untuk mempelajari } \\
\text { perkataan baharu }\end{array}$ & $56 \%$ & $44 \%$ \\
$\begin{array}{l}\text { Saya mengikuti Twitter untuk memperoleh } \\
\text { maklumat terkini }\end{array}$ & $49 \%$ & $51 \%$ \\
$\begin{array}{l}\text { Saya mengikuti Twitter untuk mendapatkan } \\
\text { panduan tatabahasa }\end{array}$ & $38 \%$ & $62 \%$ \\
\hline
\end{tabular}

Jadual 3 menunjukkan persepsi pelajar tentang penggunaan Twitter dalam pengajaran Bahasa Inggeris melalui laman e-pembelajaran. Peratusan pelajar yang menyukai Twitter dilihat lebih rendah berbanding media sosial lain. Hanya 56\% bersetuju bahawa mereka mengikuti Twitter untuk mempelajari perkataan baharu, manakala 49\% mengikuti Twitter untuk memperoleh maklumat terkini. Selain itu, hanya $38 \%$ pelajar mengikuti Twitter untuk mendapatkan panduan tatabahasa. Twitter dianggap lebih sesuai untuk mempelajari perkataan baru memandangkan setiap kandungan yang dihantar oleh pengguna tidak boleh melebihi 140 abjad (Kop, 2011). Kekangan ini menyebabkan penggunaannya untuk tujuan lain seperti meningkatkan kemahiran menulis dan bertutur mungkin tidak akan membuahkan hasil yang baik.

Jadual 4

Persepsi pelajar terhadap YouTube

\begin{tabular}{lcc}
\hline \multicolumn{1}{c}{ Pernyataan } & Setuju & Tidak Setuju \\
\hline $\begin{array}{l}\text { Video YouTube membantu saya dalam } \\
\text { kemahiran bertutur }\end{array}$ & $75 \%$ & $25 \%$ \\
$\begin{array}{l}\text { Video YouTube membantu saya memahami } \\
\text { tatabahasa }\end{array}$ & $45 \%$ & $55 \%$ \\
$\begin{array}{l}\text { Video YouTube membantu saya dalam } \\
\text { kemahiran menulis }\end{array}$ & $41 \%$ & $59 \%$ \\
\hline
\end{tabular}


Jadual 4 menunjukkan persepi pelajar tentang penggunaan video YouTube dalam pengajaran Bahasa Inggeris yang diberikan melalui sistem e-pembelajaran. Sebanyak $75 \%$ pelajar bersetuju bahawa video-video yang ditonton melalui YouTube banyak membantu mereka dalam kemahiran bertutur. Terdapat banyak video yang mengajar tentang sebutan yang betul dan juga teknik pengucapan yang berkesan. Walau bagaimanapun, hanya $45 \%$ pelajar berpendapat video YouTube membantu mereka memahami tatabahasa. Selain itu, $41 \%$ pelajar juga berpendapat video YouTube membantu mereka dari segi kemahiran menulis. Walaupun terdapat videovideo menarik tentang tatabahasa dan kemahiran menulis yang diberikan, pelajar secara amnya berpendapat bahawa media sosial ini lebih sesuai digunakan untuk memantapkan penguasaan kemahiran bertutur mereka.

\section{Kekuatan dan Kelemahan Media Sosial}

Berdasarkan dapatan kajian, beberapa kekuatan dan kelemahan media sosial dalam pembelajaran Bahasa Inggeris telah dikenal pasti. Dari segi kekuatan, media sosial didapati membantu perkongsian ilmu dan maklumat secara terbuka. Pelajar tidak berasa malu kerana interaksi berlangsung secara maya, dan bukannya bersemuka. Selain itu, media sosial juga memberikan konteks pembelajaran bahasa yang baik. Perbincangan melalui Facebook, sebagai contoh, membantu pelajar berhubung dengan pelajar dari luar negara yang memerlukan mereka untuk menggunakan Bahasa Inggeris dengan betul.

Dari segi kelemahan media sosial pula, penggunaan aplikasi ini boleh mengurangkan kawalan terhadap aktiviti pelajar. Pengajar juga mungkin akan menghadapi kesukaran untuk mengawal pelajar dalam media sosial. Isu akses kepada internet juga boleh membantutkan penggunaan media sosial dalam pembelajaran. Di samping itu, media sosial juga boleh menjadi ancaman kepada penggunaan tatabahasa yang betul. Pelajar mungkin akan taksub dengan penggunaan "bahasa Internet" atau "bahasa rojak". Situasi ini akan menjejaskan penguasaan bahasa para pelajar. Isu kerahsiaan peribadi juga perlu diberi perhatian. Pelajar akan berasa tidak selesa untuk berikteraksi sekiranya maklumat peribadi mereka tidak dilindungi daripada orang awam yang tidak dikenali. Lantaran itu, panduan penggunaan media sosial dalam pembelajaran perlu diwujudkan untuk memaksimumkan potensi aplikasi media sosial.

\section{Rumusan}

Secara keseluruhannya, kajian ini telah mengenal pasti persepi pelajar prasiswazah terhadap penggunaan media sosial dalam pengajaran Bahasa Inggeris. Facebook didapati sangat popular dalam kalangan pelajar dan media sosial ini banyak digunakan untuk tujuan perbincangan. Wiki pula digunakan untuk menggalakkan perkongsian pandangan dalam penulisan. Pelajar-pelajar juga didapati dapat mempelajari struktur penulisan dengan lebih efektif melalui Wiki. Di samping itu, video-video YouTube didapati berupaya membantu pelajar meningkatkan kemahiran bertutur, manakala Twitter digunakan untuk mempelajari perkataan baru. 
Kajian ini juga telah menyenaraikan kekuatan dan kelemahan media sosial dalam pengajaran Bahasa Inggeris. Walaupun terdapat kekangan dalam penggunaannya, media sosial ternyata dapat meningkatkan minat pelajar untuk mempelajari Bahasa Inggeris. Aplikasi-aplikasi media sosial memberikan konteks dan kemudahan yang baik untuk pembelajaran bahasa. Namun, pengajar harus bijak menggunakan aplikasi-aplikasi tersebut supaya objektif yang ditetapkan dapat dicapai. Kajian lanjut tentang impak media sosial terhadap prestasi pelajar boleh dijalankan pada masa akan datang untuk membuktikan keberkesanannya dalam pembelajaran.

\section{Rujukan}

Annand, D. (2011). Social presence within the community of inquiry framework. The International Review of Research in Open and Distance Learning, 12(5), 40-56.

Azer, S. A. (2012). Can YouTube help students in learning surface anatomy? Surgical and Radiologic Anatomy, 34(5), 465-468.

Boyd, D. (2010). Streams of content, limited attention: The low of information through social media. EDUCAUSE Review, 45(5), 26-36.

Chambers, A. (2010). Computer-assisted language learning: Mapping the territory. Language Teaching, 43(1), 113-122.

Huang, H. T., \& Hung, S. T. (2009). Implementing electronic speaking portfolios: Perceptions of EFL students. British Journal of Educational Technology, 41(5), 84-88.

Hunter, R. (2011). Erasing "property lines": A collaborative notion of authorship and textual ownership on a fan Wiki. Computers and Composition: An International Journal for Teachers of Writing, 28(1), 40-56.

Kaplan, A. M., \& Haenlein, M. (2010). Users of the world, unite! The challenges and opportunities of social media. Business Horizons, 53(1), 59-68.

Kern, R. (2006). Perspectives on technology in learning and teaching languages. TESOL Quarterly, 40(1), 183-210.

Kop, R. (2011). The challenges to connectivist learning on open online networks: Learning experiences during a massive open online course. The International Review of Research in Open and Distance Learning, 12(3), 19-38.

Kesseler, G. (2009). Student-initiated attention to form in Wiki-based collaborative writing. Language Learning \& Technology, 13(1), 79-95. Retrieved from http://lt.msu.edu/vol13num1/kessler.pdf

Kessler, G., Bikowski, D., \& Boggs, J. (2012). Collaborative writing among second language learners in academic web-based projects. Language Learning and Technology, 16(1), 91-109. Retrieved from http://It.msu.edu/issues/february2012/kesslerbikowskiboggs.pdf.

Roblyer, M. D., McDaniel, M., Webb, M., Herman, J., \& Witty, J. V. (2010). Findings on Facebook in higher education: A comparison of college faculty and student uses and perceptions of social networking sites. The Internet and Higher Education, 13(3), 134-140. 
Wardrip-Fruin, N., \& Montfort, N. (2003). The new media reader. Cambridge: MIT Press.

Weller, M. (2011). A pedagogy of abundance. Spanish Journal of Pedagogy, 249, 223-236. 